\title{
CAPITAL MARKETS INTEGRATION, VOLATILITY AND PERSISTENCE
}

\author{
Joshua Aizenman
}

Working Paper No. 5241

\section{NATIONAL BUREAU OF ECONOMIC RESEARCH 1050 Massachusetts Avenue \\ Cambridge, MA 02138 \\ August 1995}

Useful comments by the seminar participants at the research department of the IDB are gratefully acknowledged. All errors are mine. This paper is part of NBER's research program in International Trade and Investment. Any opinions expressed are those of the author and not those of the National Bureau of Economic Research.

(C) 1995 by Joshua Aizenman. All rights reserved. Short sections of text, not to exceed two paragraphs, may be quoted without explicit permission provided that full credit, including $(\odot$ notice, is given to the source. 


\title{
CAPITAL MARKETS INTEGRATION,
} VOLATILITY AND PERSISTENCE

\begin{abstract}
This paper shows that volatility induces adverse first order welfare effects in countries excluded from the global capital market. This result is illustrated in a model characterized by gains from a greater division of activities, where shocks are persistent. We show that nonlinearities attributed to financial autarky explain the adverse welfare effects of volatility. We identify the parameters determining the magnitude of the loss -- it is proportional to the autocorrelation of shocks, to volatility (as measured by the standard deviation of shocks), and to the degree of product differentiation (as measured by the substitutability among intermediate products).
\end{abstract}

Joshua Aizenman

Department of Economics

6106 Rockefeller Hall

Dartmouth College

Hanover, NH 03755

and NBER 
Several empirical studies identified a negative effect of volatility on economic growth and investment. ${ }^{1}$ The purpose of this paper is to provide an economic interpretation for these findings. Our investigation points out that volatility matters (i.e., it leads to first order effects) in the presence of nonlinearities. A potential source of non-linearities is the limited integration of capital markets. Economies that exhibits positive correlation between volatility and investment when capital markets are fully integrated, experience a negative correlation with financial autarky.

In a neoclassical world, in the presence of perfect capital mobility, the restrictions imposed by available theories on the correlation between growth and uncertainty are fragile. The impact of uncertainty on growth is determined by the magnitude of various elasticities the value of which are hard to identify. For example, the impact of uncertainty on precautionary saving is ambiguous. ${ }^{2}$ A similar result applies for the case in which the risk stems from pure capital income risk (rather than labor income risk), as was shown by Mirman (1971) and Rothschild and Stiglitz (1971). Uncertainty increases the volatility of the demand for investment in the presence of irreversibilities, but it has ambiguous effects

$1 \quad$ For example, Ramey and Ramey (1994) finds substantial evidence of a negative relationship between volatility in real GDP and the average growth rate of the GDP. Constructed measures of volatility account negatively for growth rates in Barro's type of growth and investment regressions. See Aizenman and Marion (1993) for the negative effect of fiscal, monetary, and inflation volatility measures, and Hausmann (1994) for the negative contribution of terms of trade volatility.

2 As was shown by Leland (1968) and Sandmo (1970), higher volatility of future labor income has an ambiguous effect on pecuniary saving, an effect the sign of which hinges on the third derivative of the utility. This result follows from the observation that the saving decision is determined by a first-order condition that equates the discounted marginal utility across periods. The impact of uncertainty is obtained by applying the implicit function theorem to the first-order condition. This can be done using a second-order Taylor approximation of the first-order condition, which leads to third-order terms. 
on the average investment, etc. ${ }^{3}$ Hence, the predicted correlation between uncertainty and growth in a neoclassical framework is ambiguous, and it is hard to provide an interpretation of the empirical findings without taking a position on the magnitude of various elasticities the value of which is hard to assess.

The picture differs, however, if one recognizes that imperfect capital mobility (either due to sovereign risk or due to moral hazard problems) leads to credit rationing. The purpose of this paper is to point out that credit rationing may induce a negative correlation between uncertainty and growth, even in instances where this correlation would have been positive had credit markets been fully integrated. The intuition behind these results is that the credit ceiling induces nonlinear intertemporal budget constraints, frequently leading to a concave dependency of investment on shocks. Non linearity accounts for both the negative correlation between volatility and investment, as well as for the presence of first order costs of volatility. With full integration of capital markets the welfare effects of uncertainty are frequently of a second order of magnitude. Yet, when credit ceilings are binding, the non-linearities induce a first order welfare cost of uncertainty.

Our approach cautions that swings in the integration of capital markets, as observed in Mexico and other Latin American countries in the last twenty years, hamper growth and reduce welfare. It suggests that policies reducing these swings may generate large positive externalities, by linearizing intertemporal budget constraints. This, in term, will reduce the adverse effects of volatility on investment, growth and welfare.

3 If productivity shocks are positively correlated, irreversibility increases the investment in good times, and reduces the investment in bad times. Its net effect on the average investment, however, is determined by elasticity considerations. The behavior of investment under irreversibilities has been investigated by Bernanke (1983), McDonald and Siegel (1986), Pindyck and Solimano (1993) and the references there in. An insightful review of the topic is provided by Dixit and Pindyck (1994). If the producer has market power the analysis is more involved [see Caballero (1991)]. 
Section 1 reviews the model. We illustrate the implications of non-linear intertemporal budget constraints in an economy where the number of activities in the economy is endogenously determined. This point is shown in the context of Ethier's (1982) approach, where there are gains from deepening the division of activities in the economy, as is frequently the case with the modern manufacturing sector. ${ }^{4}$ Section 2 characterizes the equilibrium if the economy is fully integrated with the global capital market. In Section 3 we review the equilibrium with financial autarky. Section 4 compares expected utility and investment patterns in the two regimes. Section 5 provides concluding remarks regarding interpretation.

\section{The Model}

There is a large literature pointing out that incomplete information, enforcement problems and sovereign risk frequently lead to external credit rationing, where the ultimate budget constraints of a country are nonlinear. ${ }^{5}$ We turn now to a simple example illustrating that the degree of capital mobility may be a key determinant in explaining the adverse implications of volatility on investment. For the sake of simplicity we focus on the average investment in a model where there is no intrinsic growth, and the focus of the analysis is on the "level effects" of uncertainty. One can extend the "level effect" results into "rate effects" following the methodology of the endogenous growth literature. ${ }^{6}$

4 Similar results can be illustrated in models where the gains from division of activities are introduced on the consumption side, in the form of "love of varieties," as in Dixit and Stiglitz (1977). 5 See, for example, the papers and the references in Freknel et al (1989).

6 This literature was triggered by Lucas (1988) and Romer (1986), who considered the implications of learning by doing and the accumulation of knowledge on generating self-sustained, endogenous growth. Recognizing that Solow's results are driven by the diminishing marginal productivity of capital in a onegood, two-inputs neoclassical model, the departure point of the new literature is to apply multi activities models where diminishing marginal productivity does not hold. The necessary condition for generating 
Consider an overlapping generation model. The representative consumer born at time $t$ lives for two periods. He works only in the first period of life, supplying inelastically $L_{0}$ units of labor. We assume a simple additive utility function:

$$
\text { (1) } \quad U_{t}=C_{1, t}+\frac{C_{2, t+1}}{1+\rho}
$$

where $C_{1, t}$ and $C_{2, t+1}$ stands for the consumption of generation $\mathrm{t}$ at time $\mathrm{t}$ and time $\mathrm{t}+1$, respectively. The size of each generation is time invariant. Generation $t$ can produce the final product using two processes: first, it can use a Ricardian technology, where one unit of labor at time t produces one unit of the final product

$$
\text { (2) } Z_{t}=L_{t}
$$

Alternatively, generation thas access to investment opportunities, modeled along Ethier (1982). Investment in intermediate products at time $t$ will enable agents of generation $t$ a costlessly "assembly" of intermediate products to the final product in period $t+1$. The production of an intermediate product $r$ $(1 \leq \mathrm{r} \leq \mathrm{m})$ requires investment $\mathrm{K}$. For exposition simplicity we assume that capital fully depreciates after one period. Investment $\mathrm{K}$ in intermediate product $\mathrm{r}$ at time $\mathrm{t}$ will yield next period a supply of intermediate product $\mathrm{r}$ given by ${ }^{7}$

(3) $\quad X_{t+1, r}=A \mu_{t+1}$

sustained growth is weaker - the real return for the accumable input (like physical capital, human capital, etc.) should exceed the discount rate.

7 We assume an endowment model, where labor $L_{t+1}$ is not involved in the supply of the intermediate products (3). This specification separates the budget constraints of the overlapping generations, simplifying presentation. 
where $A$ is a constant, and $\mu$ is a productivity disturbance. The assembly of $\mathrm{m}$ intermediate products lead to the final output of

$$
Z=b \theta^{-1}[D]^{\theta} \text { for } D=\left[\sum_{i=1}^{m}\left\{X_{i}\right\}^{\alpha}\right]^{1 / \alpha}
$$

for $0<\theta<1 ; 0<\alpha<1 ; i=1, \ldots, \mathrm{m}$. The relative magnitude of $\theta$ and $\alpha$ determines the patterns of complementary/substitutability between the various intermediate products. Henceforth we assume that $\theta<\alpha$, implying that there is complementary between the various intermediate products. ${ }^{8}$ In a symmetric equilibrium where the supply of all intermediate products equals $X_{r}$, the supply of the final good is

(4) $Z=b \theta^{-1} m^{\theta / \alpha}\left[X_{r}\right]^{\theta}$

Hence, when intermediate inputs are complements the production function is characterized by decreasing returns to the division of activities. ${ }^{9}$

Productivity $\mu$ is assumed to follow a Markov switching process:

8 If $0<\theta<\alpha$, then they are "complements": the presence of a new intermediate input increases the marginal product of other intermediate inputs. Notice that the elasticity of technical substitution between two intermediate products [1/(1- $\alpha)]$ depends only on $\alpha$, and is always positive even when they are "complements."

9 As we approach independent inputs $(\theta=\alpha)$, the diminishing returns to the division of activities weakens. In the limiting case of independence final output is proportional to the number of activities. This is also the case where the marginal productivity of investment in new activities is constant, leading to zero or unbounded investment demand. Our assumption that inputs are complements rules out this possibility. 
(5) $\mu_{t}=\left\{\begin{array}{c}1+h \\ \text { or } \\ 1-h\end{array}\right.$ for $\quad 0 \leq h \leq 1$.

where the transition probability of remaining (switching) in a given (to the second state) state is $\phi$ $(1-\phi)$. It can be verified that the asymptotic variance of productivity disturbances is $h^{2}$, and the asymptotic autocorrelation of productivity shocks is $2 \phi-1$. Hence, we can use $h$ as a volatility measure, and $2 \phi-1$ as a measure of persistence, where $\phi=.5$ corresponds to the absence of persistence. An important characteristic of this specification is that the relevance of the present regime for the nature of future regimes declines geometrically over time at a rate determined by the persistence of the shocks. Each time we enter a regime, the evolution of the future is independent of the past. As long as the probability of reaching each regime is positive, the long-run stochastic properties are independent of the initial conditions.

Equation (5) specifies a two states economy - high and low productivity. It can be shown that the asymptotic probability of the occurrence of a given state is one-half, and is independent of the nature of the initial productivity. This suggests that a useful way of analyzing welfare is to focus on the asymptotic expected utility, as its value is independent of the initial productivity conditions. We adapt this approach throughout the analysis, as it allows a state independent regime comparison. We will assume that shocks are persistent $(\phi>0.5)$, as is revealed in the data. With persistence, we show that high (low) productivity today induces agents to anticipate high (low) future productivity, magnifying the adjustment of investment to a given shock. The focus on asymptotic expected utility enabled us to "average" the states of high and low productivity with equal weights, providing information on the "average," long run effect of volatility.

A consumer born at time $t$ uses his labor endowment to produce the final product (using the Ricardian technology), and determines how much he consumes at time $t$, and how much he invests in intermediate products that will yield the final product at period $t+1$. We solve the optimal behavior for two cases: full integration of capital markets, and financial autarky. 


\section{Full integration of capital markets}

Full credit market integration implies that generation $t$ can borrow at a real interest rate $\rho$, as long as the repayment at time $t+1$ falls short of the expected output at period $t+1$. The budget constraints for a representative agent born at time $\mathrm{t}$ are

a. $\quad C_{1, t}=L_{0}+B_{t}-m_{t+1} K$

(6)

b. $\quad C_{2, t}=b \theta^{-1}\left[m_{t+1}\right]^{\theta / \alpha}\left[A \mu_{t+1}\right]^{\theta}-B_{t}(1+\rho)$

for $B_{t} \leq \frac{b \theta^{-1}\left[m_{t+1}\right]^{\theta / \alpha}\left[A \mu_{t+1}\right]^{\theta}}{1+\rho} E_{t}\left[\left\{\mu_{t+1}\right\}^{\theta}\right]$

where $B$ is borrowing, and $E_{t}[]$ is the expectation operator (conditional on information available at time

t). Hence, with capital mobility investment is not constrained by contemporaneous resources.

There is free entry to the production of intermediate products - each agent can invest (or participate in investment by pooling funds) in intermediate products. In the symmetric equilibrium each agent specializes at time $t$ in the production of few intermediate products, to be sold at time $t+1$, and will buy a basket of all available intermediate products. ${ }^{10}$ The optimal investment plan is solved recursively. We identify first the market price for variety $r$ in period $t+1$. Next, we solve for the investment level (i.e., for $m_{t+1}$, the number of varieties of intermediate products in period $t+1$ ) by invoking the condition that the expected yield on investing in intermediate products equals the interest rate $\rho$.

Equating the price of intermediate products to its marginal productivity implies a demand for variety $r$ given by

10 Note that this implies that period $t+1$ budget constraint (6b) includes two extra terms that adds up to zero. 
(7)

$$
X_{t+1, r}^{d}=\left[\frac{b}{p_{t+1, r}}\right]^{\sigma}\left[D_{t+1}\right]^{(\theta-\alpha) \sigma}, \text { for } \sigma=1 /(1-\alpha)
$$

Applying (4) and (7) we get that for a symmetric equilibrium where supply equals demand

$$
X_{t+1, r}=\left[\frac{b}{p_{t+1, r}}\right]^{\varepsilon}\left[m_{t+1}\right]^{(\theta-\alpha) \varepsilon / \alpha}, \text { for } \varepsilon=1 /(1-\theta)
$$

Applying (3) and (7') we solve for the price of the representative variety at time $t+1$

(8) $\quad p_{t+1, r}=\frac{b}{\left[A \mu_{t+1}\right]^{1 / \varepsilon}}\left[m_{t+1}\right]^{(\theta-\alpha) / \alpha}$

The optimal investment at time $t$ (i.e., $m$ ) is determined by the condition of rents dissipation:

$$
E_{t}\left[p_{t+1, r} X_{t+1, r}\right]=(1+\rho) K
$$

Applying (3), (8) and (9) we infer that the number of varieties invested by generation $t$ is:

$$
m_{t+1}=\left[\frac{b A^{\theta} E_{t}\left[\left(\mu_{t+1}\right)^{\theta}\right]}{K(1+\rho)}\right]^{\alpha /(\alpha-\theta)}
$$

Henceforth we assume that $\frac{b A^{\theta}}{K(1+\rho)}>1$. This assures that in the absence of uncertainty the investment is positive ( $m \geq 1){ }^{11}$ Applying (5) and (10) we infer the actual investment in period $t$ is

11 Note that (10) implies that the aggregate investment increases with $\theta / \alpha$. This follows from the observation that higher $\theta / \alpha$ reduces the diminishing marginal productivity of the division of activities, $m$ [as can be seen by $\left.\left(4^{\prime}\right)\right]$. 


$$
\left(10^{\prime}\right) \quad m_{t+1}=\left\{\begin{array}{l}
{\left[\frac{b A^{\theta} E_{t}\left[\phi(1+h)^{\theta}+(1-\phi)(1-h)^{\theta}\right]}{K(1+\rho)}\right]^{\alpha /(\alpha-\theta)} \text { if } \mu_{t}=1+h} \\
{\left[\frac{b A^{\theta} E_{t}\left[\phi(1-h)^{\theta}+(1-\phi)(1+h)^{\theta}\right]}{K(1+\rho)}\right]^{\alpha /(\alpha-\theta)} \quad \text { if } \mu_{t}=1-h}
\end{array}\right.
$$

With persistence ( $\phi>0.5$ ), if productivity at time $t$ is high, investment will be high, and vice versa. ${ }^{12}$ Applying (1), (6) and (10) we infer that the expected utility is:

$$
E_{t}\left[U_{t}\right]=L_{0}-K m_{t+1}+\frac{b}{\theta} \frac{\left\{m_{t+1}\right\}^{\theta / \alpha} E_{t}\left[\left(A \mu_{t+1}\right)^{\theta}\right]}{1+\rho}
$$

Applying (10) and (11), collecting terms, the expected utility of generation t is reduced to

$$
E_{t}\left[U_{t}\right]=L_{0}+C_{0}\left(\frac{1}{\theta}-1\right)\left\{E_{t}\left[\left(\mu_{t+1}\right)^{\theta}\right]\right\}^{\alpha /(\alpha-\theta)} \text { for } C_{0}=\left\{\frac{b A^{\theta}}{(1+\rho) K^{\theta / \alpha}}\right\}^{\alpha /(\alpha-\theta)} .
$$

Alternatively, applying (10) to (11) we infer that

$$
E_{t}\left[U_{t}\right]=L_{0}+\left(\frac{1}{\theta}-1\right) K m_{t+1}
$$

The expected utility depends linearly on the equilibrium aggregate investment. ${ }^{13}$

12 Note that $\operatorname{sign}\left[\phi(1+h)^{\theta}+(1-\phi)(1-h)^{\theta}\right]=\operatorname{sign}[2 \phi-1]$ for $\mathrm{h}>0$.

13 The second term in (12') measures the utility attributed to the capacity of each generation to assemble freely the final goods from the traded intermediate products. In specifying the model we assumed implicitly that this capacity is non-traded, in the sense that each generation is endowed with this ability. If this capacity is traded [as is the case if there is a certain capital good used in the 
Applying the stochastic properties of productivity to (12) we infer that the expected utility of generation $\mathrm{t}$ with capital mobility (indexed $C M$ ) is

$$
E_{t}\left[U_{t}\right]_{\mid C M}= \begin{cases}L_{0}+C_{0}\left(\frac{1}{\theta}-1\right)\left\{\phi(1+h)^{\theta}+(1-\phi)(1-h)^{\theta}\right\}^{\alpha /(\alpha-\theta)} & \text { if } \quad \mu_{t}=1+h \\ L_{0}+C_{0}\left(\frac{1}{\theta}-1\right)\left\{\phi(1-h)^{\theta}+(1-\phi)(1+h)^{\theta}\right\}^{\alpha /(\alpha-\theta)} & \text { if } \quad \mu_{t}=1-h\end{cases}
$$

Note that the asymptotic probability of each state is half. Hence, the asymptotic expected utility with capital mobility is the average of the two possibilities outlined in (13)

$$
\begin{aligned}
& E_{0}[U]_{\mid C M}= \\
& L_{0}+0.5 C_{0}\left(\frac{1}{\theta}-1\right)\left[\left\{\phi(1+h)^{\theta}+(1-\phi)(1-h)^{\theta}\right\}^{\alpha /(\alpha-\theta)}+\left\{\phi(1-h)^{\theta}+(1-\phi)(1+h)^{\theta}\right\}^{\alpha /(\alpha-\theta)}\right]
\end{aligned}
$$

where $E_{0}$ stands for the asymptotic expectation operator - the expected value of a variable far in the future (formally, $E_{0}[X]=\lim \underset{j \rightarrow \infty}{\longrightarrow} E_{0}\left[X_{j}\right]$ ). The second term in (14) measures the expected gains

assembly], generation $t$ would purchase this capacity from generation $t-1$, and will sell it to generation $t+1$. Our analysis continues to apply to this case, although one should modify the intertemporal budget constraints to reflect the inter generation trade added by the need to purchase this capacity. Our model can be also specified in the context of a "love for varieties" approach, as in Dixit-Stiglitz (1977), where the production of each variety requires a set up cost $\mathrm{K}$. The reduced form utility in such a specification resembles (12'), where the second term measures the utility attributed to the consumption of varieties [see Aizenman (1994) for a version of such a model dealing with the impact of volatility on global diversification in the presence of multinationals]. 
attributed to investment in intermediate products. It depends negatively on the elasticity of the production function with respect to a representative intermediate product.

To evaluate the importance of capital mobility, we focus on the case where in the absence of uncertainty the investment demand at period t equals the entire generation's t endowment. In these circumstances, any further increase in investment demand would be financed by external borrowing if the country has full access to the global capital market. With financial autarky, the resource constraint is binding, and the investment will not increase beyond the endowment. Formally, we assume that

$$
L_{0}=K m_{0} \text { where } m_{0}=\left[\frac{b A^{\theta}}{K(1+\rho)}\right]^{\alpha /(\alpha-\theta)} \text {. Alternatively, that } L_{0}=C_{0}
$$

Applying (14) and (15) we infer that in these circumstances the asymptotic expected utility with capital mobility is 14

$E_{0}[U]_{\mid C M}=$

$C_{0}\left[1+0.5\left(\frac{1}{\theta}-1\right)\left[\left\{\phi(1+h)^{\theta}+(1-\phi)(1-h)^{\theta}\right\}^{\alpha /(\alpha-\theta)}+\left\{\phi(1-h)^{\theta}+(1-\phi)(1+h)^{\theta}\right\}^{\alpha /(\alpha-\theta)}\right]\right] \cong$

$0.5 C_{0} \frac{\alpha(1-\theta)}{\alpha-\theta}\left[\frac{\theta}{\alpha-\theta}(2 \phi-1)+\theta-1\right] h^{2}$

14 The last line in (14') is a second order approximation of the expected utility. Note that in the absence of persistence of shocks $(\phi=0.5)$, volatility reduces average investment. If persistence is significant enough, volatility increases average investment. 


\section{Financial autarky}

With financial autarky the periodic budget constraints facing a representative agent of generation $t$ are

$$
\begin{aligned}
& C_{1, t}=L_{0}-m_{t+1} K ; \quad L_{0} \geq m_{t+1} K \\
& C_{2, t}=b \theta^{-1}\left[m_{t+1}\right]^{\theta / \alpha}\left[A \mu_{t+1}\right]^{\theta}
\end{aligned}
$$

Applying (10'), it follows that the if productivity is low at time $t$, there is no shortage of funds for investment, as the demand for investment at time $t$ falls short of the available funds. In these circumstances the investment is given by the second line in $\left(10^{\prime}\right)$, and the expected utility next period is given by the second line in (13). If productivity in period $t$ is high, however, there is shortage of loanable funds. In these circumstances investment exhausts all available funds, and the future number of varieties is $\mathrm{m}_{0}$. If productivity is high in period $\mathrm{t}$, the expected utility with financial autarky (denoted by $F A$ ) equal $\mathrm{s}^{15}$

$$
\text { (17) } E_{t}\left[U_{t} \mid \mu_{t}=1+h\right]_{\mid F A}=L_{0}-K m_{0}+\frac{b}{\theta} \frac{\left\{m_{0}\right\}^{\theta / \alpha} E_{t}\left[\left(A \mu_{t+1}\right)^{\theta}\right]}{1+\rho}=\frac{C_{0}}{\theta} E_{t}\left[\left(\mu_{t+1}\right)^{\theta}\right]
$$

Thus, with financial autarky, the expected utility is

$$
E_{t}\left[U_{t}\right]_{\mid F A}= \begin{cases}\frac{C_{0}}{\theta}\left[\phi(1+h)^{\theta}+(1-\phi)(1-h)^{\theta}\right] & \text { if } \mu_{t}=1+h \\ C_{0}\left[1+\left(\frac{1}{\theta}-1\right)\left\{\phi(1-h)^{\theta}+(1-\phi)(1+h)^{\theta}\right\}^{\alpha /(\alpha-\theta)}\right] & \text { if } \quad \mu_{t}=1-h\end{cases}
$$

15 The notation $E_{t}\left[U_{t} \mid H\right]$ denotes the expected value conditional on information $\mathrm{H}$. The final from of (17) is obtained by substituting $m_{0}$ [applying (15)]. 
Recalling that the asymptotic probability of each state is half, the financial autarky asymptotic expected utility is the average of the two possibilities outlined in (18):

$$
E_{0}[U]_{\mid F A}=0.5 C_{0}\left\{\left[1+\left(\frac{1}{\theta}-1\right)\left\{\phi(1-h)^{\theta}+(1-\phi)(1+h)^{\theta}\right\}^{\alpha /(\alpha-\theta)}\right]+\frac{1}{\theta}\left[\phi(1+h)^{\theta}+(1-\phi)(1-h)^{\theta}\right]\right\}
$$

\section{Regimes comparison - non linearities and financial autarky}

We turn now to a regime comparison. Applying (14') and (19) we infer that the difference of expected utilities in the $C M$ and $F A$ regimes is

$$
\begin{aligned}
& E_{0}[U]_{\mid C M}-E_{0}[U]_{\mid F A}= \\
& 0.5 C_{0}\left\{\left[1+\left(\frac{1}{\theta}-1\right)\left\{\phi(1+h)^{\theta}+(1-\phi)(1-h)^{\theta}\right\}^{\alpha /(\alpha-\theta)}\right]-\frac{1}{\theta}\left[\phi(1+h)^{\theta}+(1-\phi)(1-h)^{\theta}\right]\right\} \cong \\
& 0.5 C_{0} \frac{1-\alpha}{\alpha-\theta}(2 \phi-1) \theta h
\end{aligned}
$$

Financial autarky leads to welfare losses proportional to volatility (as measured by $\mathrm{h}$, the asymptotic standard deviation of productivity shocks), the persistence (measured by $2 \phi-1$, the asymptotic auto correlation of productivity shocks), and the degree of product differentiation (as measured by $1-\alpha$ ). ${ }^{16}$ The welfare costs of uncertainty is determined by the number of activities discouraged by uncertainty.

16 Equation (20) implies that as intermediate products become closer substitutes (i.e., as $\alpha$ goes up), the difference between the two regimes diminishes. It can be shown that in the limiting case where $\alpha \rightarrow 1$ the welfare ranking of the two regimes is similar, though difference between the two regimes becomes of a second order magnitude (i.e., proportional to $\mathrm{h}^{2}$ ). 
Its ultimate magnitude is determined by the balance between the diminishing marginal productivity of a given intermediate product $(\theta)$ and the technological substitutability between intermediate products $(\alpha) \cdot{ }^{17}$

To gain further insight we turn to Figure 1, reporting the asymptotic expected utility relative to the utility in the absence of shocks [ $\left.U_{0}\right]$, as a function of volatility $h$. Applying (10), (12) and (17) one can confirm that the expected utility is a linear function of expected investment. Hence, Figure 1 traces also the expected investment (relative to investment in the absence of volatility) in the two regimes.

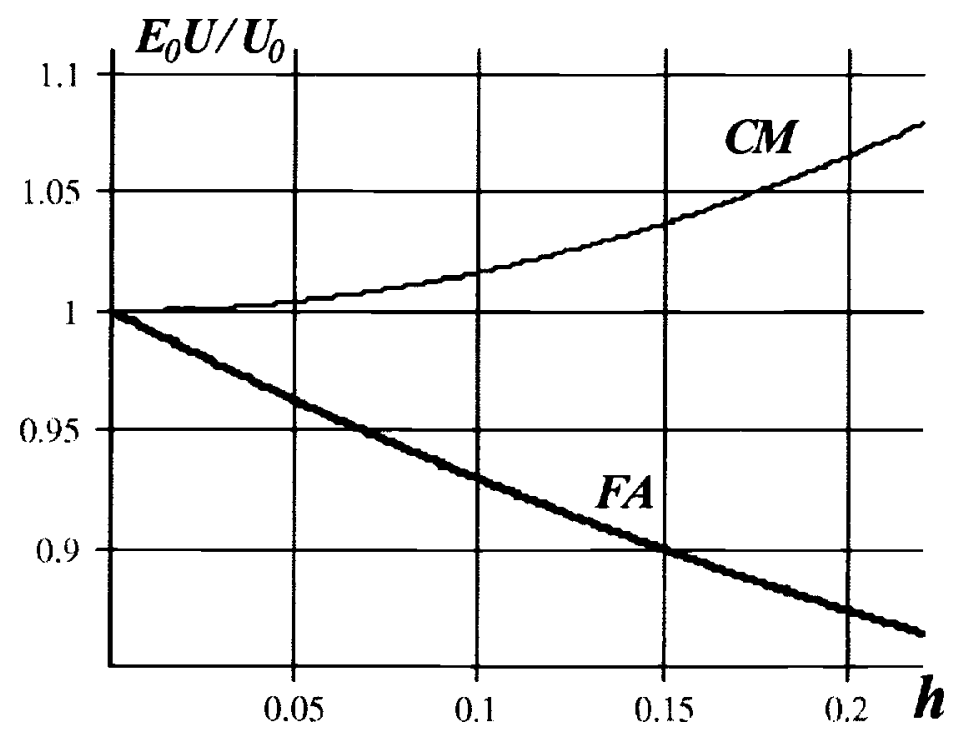

Figure 1

Expected utility, volatility and capital mobility - endogenous number of intermediate products

Drawn for $\alpha=0.4, \phi=0.9$, and $\theta=0.36$.

17 Note that the welfare cost increases as $\theta / \alpha$ goes up, because it implies lower diminishing marginal productivity of the division of activities, inducing thereby greater elasticity of the demand for investment with respect to productivity shocks. 
Note that volatility has positive but second order effects when capital markets are fully integrated (as can be seen by the tangency of the CM curve at $h=0$ with the $y=1$ curve), whereas volatility has negative first order effects with financial autarky. In the example plotted in Figure 1, the elasticity of the expected utility with respect to the asymptotic standard deviation of the productivity shock (h) around $\mathrm{h}=0$ is positive but negligible with capital mobility $\left(\mathrm{d} \log \mathrm{E}_{0} \mathrm{U} / \mathrm{d} \log (1+\mathrm{h})_{\mid C M} \approx 0.02\right)$, and negative and large in the absence of capital mobility $\left(\mathrm{d} \log \mathrm{E}_{0} \mathrm{U} / \mathrm{d} \log (1+\mathrm{h})_{\mid F A} \approx-0.77\right){ }^{18}$

Further insight can be inferred by noting that financial autarky induces non linear investment schedule, as is illustrated in Figure 2. The credit ceiling is indicated by the available present resources, $L_{0}$. The demand for investment is $I^{d}$. The actual investment is given by $I=\operatorname{Min}\left\{I^{d}(\rho), L_{0}\right\}$, where $I^{d}(\rho)$ is the investment demand at $r=\rho$. Suppose now that the demand for investment fluctuates between $I_{h}^{\mathrm{d}}$ and $I_{l}^{\mathrm{d}}$ in the high and low demand states, respectively, while the credit ceiling remains $\mathrm{L}_{0}$. The realized investment is plotted in Figure 2, panel b. The concavity of the investment implies that volatile investment demand tends to reduce average investment in the presence of credit rationing. If the probability of each state of nature is half, volatility reduces the expected investment from $\mathrm{I}_{0}$ to $\mathrm{I}^{\prime}$ (see Figure $2 \mathrm{~b}$ ). Hence, a mean-preserving increase in the volatility of investment demand tends to reduce the average investment. 
$-16-$

(a)

(b)

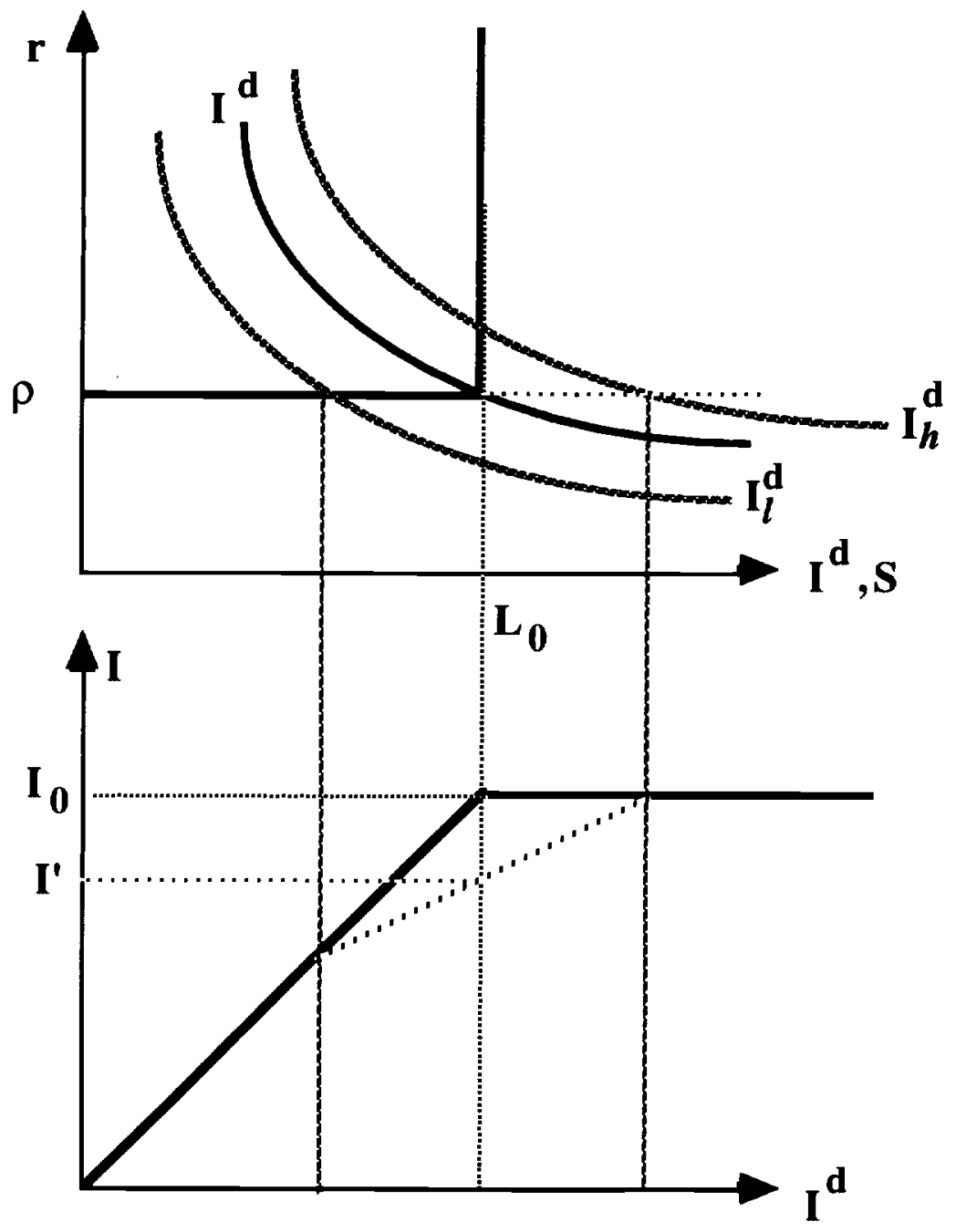

Figure 2

Volatility, non-linearities and investment 


\section{Concluding remarks}

We close the paper with comments regarding the interpretation of our model.

- Persistence of shocks and limited integration of capital markets leads to non-linearities, where volatility affects investment adversely, and the resultant costs are of a first order magnitude. The persistence of shocks implies that in good times we wish to invest more, as the future seems bright. Yet, with limited integration of capital markets, we realize only a fraction of the desired investment. In bad times, we wish to cut investment. Unlike the good times case, however, financial autarky does not inhibit the cut in investment. Hence, with financial autarky the downward adjustment is larger than the upward are, leading to non-linearities and adverse effects of uncertainty on investment.

- In tranquil times, first moments play a dominant role in explaining growth patterns. In turbulent times, first moments play a lesser role, whereas volatility assumes a greater importance in accounting for macroeconomic performance. Hence, the growth consequences of volatility are determined by the interaction between first and second moments. For example, similar volatility of international real interest affects differently countries with divergent levels of external and internal debt. Similarly, the standard deviation of terms of trade may not capture the exposure of the country to volatility; instead, the standard deviation times openness may be a better exposure measure. A long enough period of turbulent energy prices implies that countries that share similar social and developmental characteristics, but whose reliance on energy differs widely, may behave alike [i.e., in turbulent times countries exporting and importing energy may behave alike]. This will be the case if volatility of energy prices leads both groups of nations to accumulate large domestic and foreign debts. Such debt accumulation leads the borrowing economy towards financial autarky. It may also intensify the conflicts among pressure groups, producing noncooperative patterns of macro spending, leading to high and volatile inflation, tariffs, etc. 
- In a comparison of growth performance of the same country across time, focusing on the role of first moments in explaining growth may lead to disappointing results if the patterns of volatility change over time. A given volatility will have a stronger impact in periods associated with tight credit markets. 


\section{References list}

Aizenman, Joshua. and Nancy Marion. 1993. "Policy uncertainty, persistence and growth," Review of International Economics, June 1993, pp. 145 - 163.

Aizenman, Joshua. 1994. "Monetary and real shocks, productive capacity and exchange rate regimes," Economica, November, pp. 407-34.

Barro, Robert J. 1991. "Economic Growth in a Cross Section of Countries," Quarterly Journal of Economics, May.

Bernanke, Ben S. (1983), Irreversibilities, uncertainty, and cyclical movements in investment, "Quarterly Journal of Economics, 1983, 85-106.

Caballero, Ricardo J., 1991. "On the Sign of the Investment-Uncertainty Relationship," American Economic Review, pp. 279 - 288. and Robert S. Pindyck. (1992). "Uncertainty, Investment, and Industry Evolution. NBER Working Paper No. 4160.

Dixit, Avinash K. and Robert S. Pindyck. 1994. Investment Under Uncertainty, MIT Press and Joseph Stiglitz. 1977. "Monopolistic Competition and Optimum Product Diversity." American Economic Review 67: 297-308.

Frenkel, Jacob A., Michael P. Dooley and Petter Wickham (eds.), Analytical Issues in Debt, the International Monetary Fund, 1989.

Hausmann, Ricardo. 1994. "On the road to deeper integration with the north: lessons from Puerto Rico." manuscript, IDB.

Leland, Hayne, E. 1968. "Saving and Uncertainty: the Precautionary Demand for Saving," Quarterly Journal of Economics, pp. 465-473

Lucas, Robert E. Jr.. 1988. "On the Mechanism of Development Planning," Journal of Monetary Economics, pp. $3-42$.

McDonald, Robert, and Daniel R. Siegel. 1986. "The value of waiting to invest," Quarterly Journal of Economics, 101, pp. 707 - 728. 
Mirman. L. J. 1971. "Uncertainty and Optimal Consumption Decisions," Econometrica, 39, pp. 179185.

Pyndyck, Robert and Andres Solimano. 1993 "Economic instability and aggregate investment, NBER Macroeconomics Annual, pp. 259-303.

Ramey, Garey and Valerie A. Ramey. 1994. "Cross country evidence on the link between volatility and growth," NBER working paper \# 4959.

Romer, Paul M. 1986. "Increasing returns and long-run growth," Journal of Political Economy 94, pp. 1002-37.

Rothschild, M and J. Stiglitz. 1971. "Increasing Risk II: Its Economic Consequences," Journal of Economic Theory, 3 pp. 66-84.

Sandmo, A. 1970. "The effect of uncertainty on saving decisions, Review of Economic Studies, pp. 353360.

Solow, Robert M. 1956. "A Contribution to the Theory of Economic Growth," Quarterly Journal of Economics, pp. 64-94. 